\title{
SOR JUANA, VÍCTIMA DE LOS CRÍTICOS
}

\author{
PACIENCIA ONTAÑón \\ Facultad de Filosofia y Letras UNAM
}

No de todos, por supuesto. Pero sí víctima inerme de algunos, que en su intento por desentrañar la complicada personalidad y la intrincada obra de la escritora, dejan volar su fantasía, liberan sus proyecciones y delinean una figura que probablemente nunca existió y a la que ningún favor hacen con esa falsa recreación.

Me voy a referir en estas páginas a las obras de dos críticos, bien consagrados ya: Ludwig Pfandl y Octavio Paz (Sor Juana Inés de la Cruz del primero y Sor Juana Inés de la Cruz o las trampas de la fe, del segundo), libros más o menos discutidos pero, en mi opinión, no lo suficiente para dejar en claro muchas de sus aseveraciones: creo que es necesario liberar a sor Juana de toda fantasía y de toda falsa interpretación.

Antes de entrar en materia quisiera hacer unas precisiones sobre ambas. Los fines de Pfandl en su libro están claramente expresados al principio: a través de un camino "hasta ahora no recorrido», "aclarar, descortezar y separar estratos, desatar nudos, sacar a la luz del día lo que está escondido y transformar lo inconsciente en visible y consciente» ${ }^{1}$. Las conclusiones a las que el crítico llega están resumidas trescientas páginas después, en el capítulo «Summa summarum», subtitulado «El enigma resuelto»: «Juana Inés es el tipo clásico de una psiconeurótica». «Según parece, el fenómeno del misterioso talento se aclara por consiguiente por su neurótica manía meditante». «El secreto de su fuga del mundo se nos revela como una huida de la naturaleza y carácter femeninos». «Juana Inés jamás ha amado a ningún hombre, sólo a sí misma». "Sobre la oscuridad del quebranto desciende finalmente clara luz por medio de la comprobación de la fuerza del climate-

\footnotetext{
${ }^{1}$ Ludwig Pfandl, Sor Juana Inés de la Cruz. La décima musa de México, México, UNAM, 1963, ed. y prólogo de Francisco de la Maza, pág. 13. Las citas se harán por esta edición, señalando sólo el número de página.
} 
rio» (págs. 310-311). Afirmaciones tajantes que por su osadía sorprenden con incredulidad, pero que muestran las intenciones del crítico alemán: resolver de una vez para todas cualquier duda sobre la personalidad de la monja.

El libro de Octavio Paz parece tener fines diferentes, fines que serían fundamentalmente de tipo histórico y sociológico: «La comprensión de la vida de sor Juana incluye necesariamente la de la vida y la de su mundo. En este sentido, mi obra es un ensayo de restitución; pretendo restituir a su mundo, la Nueva España del siglo XVII, la vida y la obra de sor Juana» ${ }^{2}$ (un propósito que parece más sensato).

Ante dos obras sobre un mismo tema, pero con fines evidentemente diferentes, cabría la pregunta: ¿por qué contemplarlas conjuntamente? Sus fechas de edición no son muy próximas: primera edición de Pfandl, 1946 (primera edición al español, 1963); primera edición de Paz, 1982. Hasta su traducción al español, la obra de Pfandl había sido poco conocida en México. Tampoco fue muy popular a partir de la traducción, a pesar del entusiasta y encomiástico prólogo de Francisco de la Maza (quien parece seducido por los «hallazgos» de Pfandl). Sin embargo, Paz la tiene en cuenta desde las primeras páginas. En la 13 cita a los dos grandes biógrafos de sor Juana, colocados en dos extremos: Calleja, que ve a la monja «en un gradual ascenso hacia la santidad» (pág. 13) y Pfandl, que ofrece «una personalidad neurótica, en la que predominan fuertes tendencias masculinas» (id.).

Más adelante hace una crítica directa a la obra de Pfandl, aunque reconociendo aciertos ${ }^{3}$, sobre todo cuando se refiere a la personalidad de la escritora. Lo mismo que Pfandl, se refiere al «enigma» de sor Juana, término que no me parece muy apropiado. No hay tal enigma, sino desconocimiento por nuestra parte.

Un error de Paz, que se ha repetido, lamentablemente, con frecuencia, es el de considerar la obra del investigador alemán como influida por el psicoanálisis (pág. 13). La obra de Pfandl, preciso es insistir, no es una crítica psicoanalítica: como él mismo afirma, es un intento por descubrir el «enigma» de la personalidad de Juana Inés. El fin de la crítica psicoanalítica, parece ocioso precisarlo, no es el autor, sino la obra. Ésta sí tiene dos contenidos, uno consciente y el otro inconsciente, pero Pfandl nunca trabaja con

\footnotetext{
${ }^{2}$ Octavio Paz, Sor Juana Inés de la Cruz o las trampas de la fe, México, FCE, 1983, pág. 18. Todas las citas se harán por la misma edición, señalando sólo el número de página. ${ }^{3}$ «Ludwig Pfandl escribió un grueso volumen sobre sor Juana. Grueso en el sentido material y en el espiritual. No obstante, a despecho de sus exageraciones, el profesor alemán hace una observación plausible, aunque desnaturalizada por sus unilaterales conclusiones», $\mathrm{O}$. Paz, pág. 92. También afirma, y con toda razón, que «Pfandl pretende descubrir los secretos de un alma provisto de tres o cuatro libros de psiquiatría», pág. 260.
} 
ello. Trata de alcanzar el inconsciente de la monja, tarea inútil si no imposible y, naturalmente, «descubre» sólo patologías, anormalidades, cuestiones fisiológicas, que para él resultan reveladoras. Su conocimiento psicoanalítico es deficiente e incurre en errores básicos con frecuencia. Además no acude a la bibliografía que lo hubiera ayudado, sino a psicólogos de segunda categoría, a psicofisiólogos o a médicos. Todo ello confundió a la crítica literaria, ya que el libro de Pfandl fue tomado como un modelo de análisis psicoanalítico. Así, algunos comentaristas se refieren a una rama de esa forma de crítica, la dedicada al estudio del autor ${ }^{4}$. Otros la definen como estudios "clínico-biográficos», o a la obra, como un "espacio de proyección de afecciones de origen psicopatológico» ${ }^{5}$. Y todo ello, sin duda, basado en el libro de Pfandl, que parece estar claramente incluido en esas descripciones.

Es cierto que Octavio Paz también comete errores en cuestiones psicoanalíticas; una de ellas es la afirmación siguiente: «Pero ya Freud nos previno: el psicoanálisis no puede explicar enteramente la creación artística» (pág. 15) (cuando lo que dijo Freud fue todo lo contrario ${ }^{6}$ ), y algunas otras que no voy a mencionar, porque en su obra tendría menos importancia; aunque incursione aquí y allá en el psicoanálisis, su obra no pretende ser un tratado analítico.

Sin embargo, Paz no puede por menos de conceder un cierto crédito a la obra del alemán, y lo sigue -0 se deja arrastrar por él — en una serie de cuestiones acerca de la personalidad de Juana Inés que poco tienen que ver con su obra y que tampoco tienen bases psicológicas suficientes como para ser tenidas por ciertas. Éstos serían, precisamente, los puntos de coincidencia entre las dos obras, puntos que será necesario discutir en estas páginas y en los que haré más hincapié.

Voy a referirme, pues, a las cuestiones «psicológicas» más sobresalientes de los dos libros: al supuesto narcisismo de la escritora, que los dos críti-

${ }^{4}$ «Una de las provincias de esa crítica está constituida por estudios sobre la organización de la sensibilidad de un escritor, sobre su «tipo» psicológico, sobre los estímulos que más le sacuden el ánimo, sobre sus motivos conscientes o subconscientes, sobre sus preferencias mentales», Enrique Anderson Imbert, Métodos de crítica literaria, Madrid, Ediciones de la Revista de Occidente, 1969, pág. 104.

${ }_{5}$ Carlos Reis, Fundamentos y técnicas del análisis literario, Madrid, Editorial Gredos, 1981, págs. 72 y 73

6 «Las investigaciones del psicoanálisis han proyectado una ola de luz en los dominios de la mitología, la ciencia de la literatura y la psicología de los artistas... La estimación estética de la obra de arte, así como la explicación del don artístico, no son tareas para el psicoanálisis. Sin embargo, parece que el psicoanálisis está en condiciones para decir la palabra decisiva sobre todas las cuestiones que conciernen a la vida imaginaria de los hombres», Sigmund Freud, Introducción al psicoanálisis, en Jean Le Galliot, Psicoanálisis y lenguajes literarios, Buenos Aires, Hachette, 1977, pág. 40. 
cos sostienen; a su masculinidad, si no a su asexualidad; al complejo de Edipo y a las lucubraciones sobre el climaterio de sor Juana, y el efecto de éste en sus últimos años; todas ellas cuestiones biográficas, arriesgadas, mal enfocadas e imposibles de precisar.

«El narcisismo es un penoso padecimiento psíquico; sobre esto no hay duda alguna», dice Pfandl. «Más el carácter terrible de este mal, el trágico alcance de de este fenómeno de degeneración....» etc. (pág. 169). Y líneas después: «El narcisismo y la esquizofrenia poseen en común la tendencia al empobrecimiento de la sensibilidad» (pág. 170). Más tarde, este «empobrecimiento de la sensibilidad» se convierte en «empobrecimiento afectivo» (pág. 175), lo cual es muy diferente, y que es tan poco comprobable como lo anterior. $\mathrm{Al} \mathrm{mismo} \mathrm{tiempo,} \mathrm{incurre} \mathrm{en} \mathrm{contradicciones} \mathrm{llamativas,} \mathrm{ya} \mathrm{que,}$ en otra ocasión se refiere a la «sensibilidad excesiva» de la escritora (pág. 181).

A partir de este diagnóstico «indiscutible», le resulta fácil a Pfandl interpretar la poesía amorosa de sor Juana, «casi incomprensible» (pág. 91), u observar el empobrecimiento afectivo de la escritora en la carta a sor Filotea; y también, de ahí, interpretar los cinco «malos sonetos» picarescos, «cinco malcriados íncubos» (pág. 175), producto indudable de «un anormal estado de sensibilidad» (id.).

Todos estos conceptos no merecerían el menor comentario; por sí solos se descartan. Sin embargo, Octavio Paz los retoma, y aunque los califica como interpretaciones «obsesivas y monomaniacas» (yo las calificaría de ignorantes y osadas), afirma que «el erudito alemán acierta a veces» (pág. 93). «La intuición de Pfandl debe completarse y corregirse» (pág. 94). Pero el narcisismo queda aceptado («y siempre un narcisismo exaltado», pág. 288). Más tarde incurre en un frase contradictoria: «su narcisismo era la otra cara de su aborrecimiento de sí misma» (pág. 599), con la que se demuestra que también Paz incursiona en la ciencia psicoanalítica con poco conocimiento de ella: el narcisismo es la oposición al autoaborrecimiento.

El problema no puede tratarse con frivolidad. «El estudio directo del narcisismo tropieza con dificultades insuperables», dijo Freud ${ }^{7}$. Pero ambos críticos ignoraron (o confundieron) el narcisismo con el complejo narcisis$t a$, relacionado estrechamente con los elementos regresivos del arte. Toda creación artística engloba una introspección que conduce a una profunda re-

\footnotetext{
7 Sigmund Freud, «Introducción al narcisismo», en Obras completas, Madrid, Biblioteca Nueva, 1973, tomo II, pág. 2022.
} 
gresión del artista. «La obra, como el sueño, es una acción replegada». El artista es, pues, un introvertido con tendencias al aislamiento. Pero su regresión, relacionada, sí, con el narcisismo, no es perenne, sino parcialmente duradera, absolutamente necesaria para el fenómeno de la creación $\mathrm{y}$, en ese sentido, normal ${ }^{8}$.

Otra cuestión peligrosa que los dos críticos abordan, y que debe de tomarse con muchas precauciones, es la supuesta masculinidad de Juana Inés. Pfandl anuncia que lo que algunos de sus biógrafos han insinuado, él lo va a tratar en profundidad, en «su psíquico fundamento» (pág. 95). Y así ve las actitudes de la niña Juana, al querer vestirse de varón para asistir a las escuelas que no admiten niñas, como definitivamente masculinas. Su brillo de criatura prodigio es también para él cáracterística varonil (pág. 97). La adulta, «queda desesperadamente atrapada por su neurótica actitud frente al otro sexo, al cual debería pertenecer y al que tiene que odiar, puesto que no puede formar parte de él» (pág. 97). El crítico se refiere con horror a la cadena de diecisiete redondillas en las que la escritora, en un tono «tan pronto irónicamente cáustico como groseramente injurioso» (pág. 101), culpa a los hombres de la degradación de la mujer. Y poco después se refiere a la «lucha a la par tan inconsciente como tenaz contra los hombres» (pág. 102; la cursiva es mía), prueba muy clara del desconocimiento psicoanalítico del crítico: los ataques a los hombres en las famosas redondillas son abiertos, declarados, agresivos; nada inconsciente existe en ellos; todo está bien pensado, meditado, expresado con plena claridad.

Las explicaciones acerca del origen de la masculinidad infantil de la niña son fantasías inadmisibles («Este complejo pudo haber sido adquirido por la contemplación del cuerpo infantil de aquél [el hermano], produciéndose así la traumática experiencia de la presunta imperfección», (pág. 103). Con estos circunloquios se refiere Pfandl, sin duda, a un término freudiano, la «envidia del pene», un problema de psicología profunda, cuyos resultados no tienen que ser necesariamente el complejo de masculinidad; las consecuencias pueden ser una abanico de posibilidades, entre las que está, sí, el complejo de masculinidad, pero también una feminidad normal y muchas otras $^{9}$ (además de que la suposición de la contemplación, por parte de Juana, de su hermano, es completamente hipotética y gratuita).

\footnotetext{
${ }^{8}$ Cfr. Charles Baudouin, Psicoanálisis del arte, Buenos Aires, Editorial Psique, 1972, capítulo IV, «Narcisismo, introversión y complejo de aislamiento», págs. 80-92.

${ }^{9}$ Cfr. Sigmund Freud, «La feminidad», en Obras completas, III, págs. 3164-3178.
} 
Es evidente que Pfandl no tiene muy claro qué es el complejo de masculinidad, ya que páginas después describe actitudes de Juana que mostrarían lo contrario. Habla, por ejemplo, de «un secreto anhelo de maternidad» (pág. 146), que no sería muy varonil, por cierto. Los símbolos persistentes en el Sueño, de procreación, nacimiento y maternidad (pág. 91), tampoco lo parecerían. Las observaciones que la monja relata, sobre un trompo, un juego de alfileres o un huevo batido en manteca, los analiza el alemán como símbolos sexuales (con gran indignación de Paz, pág. 95), en una interpretación ciertamente primitiva. Pero, lo que es más curioso, en caso de poder aceptarse tales interpretaciones, es que nos mostrarían una personalidad obsesionada por símbolos fálicos, lo cual tampoco sería una muestra de masculinización.

A dicha virilidad, o «negación psíquica e intelectual de su sexo» (pág. 188), se sumó, según Pfandl, una nueva des-sexualización que tendría lugar al ingresar la escritora al convento. "Como no puede ser hombre, tampoco puede ser mujer, sino mejor un ser sin sexo» (pág. 188). Y la prueba más contundente para Pfandl de tan trágico estado, es el poemita dirigido al peruano Navarrete, admirador suyo que le obsequia un par de búcaros de barro, junto con unos versos, infortunadamente hoy desaparecidos. Los de sor Juana que Pfandl incluye, un fragmento del poema, («Yo no entiendo de esas cosas;/Sólo sé que aquí me vine / Porque, si es que soy mujer, / Ninguno lo verifique»), prueban para él, «como a la luz de un rayo, toda la tragedia psíquica de Juana Inés». Para mí suponen lo contrario: la actitud de una monja, celosa de su castidad, que no quiere que nadie intervenga en su sexualidad, exhibiendo, inclusive, una cierta coquetería con ello. Naturalmente, es imposible opinar en ningún sentido sin conocer dos cosas: una, el poemilla de Navarrete; dos, qué eran esos «barros». En el Diccionario de Autoridades de 1726, «barro» es «el vaso que se hace de diferentes hechuras y tamaños, de tierra olorosa para beber agua». Lo cual lleva a recordar la profusa riqueza de formas y tamaños, con elementos casi siempre sexuales, de los vasos incaicos prehispánicos, que actualmente se siguen reproduciendo con la misma temática. Si hoy se emplean con tanta frecuencia los elementos sexuales en las jarras y vasos peruanos, herencia, sin duda, de los antecedentes antiguos, lo más probable es que el gusto por esas ornamentaciones fuera también común en el siglo XVII. En ese sentido, los versos de sor Juana tendrían un significado claro: las reproducciones de órganos masculinos o de actitudes sexuales «no las entiende»; pero su entrada al convento ha sido para tratar de que esas insinuaciones masculinas a la sexualidad queden aparte. Naturalmente que todo esto sólo podría comprobarse mediante el conocimiento de los versos de Navarrete, viendo si en ellos existía 
alguna insinuación amorosa atrevida. Pero, de ninguna manera se podría verificar, a través de ello, «la tragedia psíquica» de sor Juana, sino más bien todo lo contrario. Las conclusiones de Pfandl, además, cuando caracteriza a la monja de «fundición defectuosa», poco tiene de psicológica, ya que el término 'fundición' supone un defecto de origen, independiente de las alteraciones psíquicas posteriores.

En el apartado «La servidumbre y sus consecuencias» (págs. 176-185), Pfandl entra en complicadas teorías en cuanto a las relaciones entre mujeres narcisistas intelectuales, para explicar el afecto de Juana Inés por la condesa de Paredes. El crítico emprende la «tarea muy poco grata» de «tener que valerse de las propias poesías de nuestra Juana Inés para mostrar que ella da también deplorables ejemplos de servidumbre amorosa» (pág. 177). ¿Por qué poco grata tarea? Estudiar la poesía de un escritor debería ser un fin, por sí mismo. Pero no se hace el menor análisis de los poemas que se incluyen, sino sólo algunos comentarios que parecen partir de ideas preconcebidas; las conclusión a la que se llega es que existe «una velada confesión de masoquismo» (pág. 180), o que la escritora «se extravía por el territorio del ridículo» (pág. 181), pero con un contenido donde predomina «el no-poder-de otro modo, del tener-que amar, de la servidumbre-del-ser» (pág. 181). Como no se hace ningún análisis para apoyar estas aserciones, todo queda como apreciaciones personales, que no convencen por sí mismas. La conclusión del estudioso, en este subcapítulo, es que Juana Inés ofrece todos sus sentimientos a la vista, y que éstos "se manifiestan precisa y catagóricamente, unívoca e innegablemente». Es decir, que existió una relación lesbiana entre la escritora y la virreina, que aquélla dejó bien clara en sus poemas. Aquí las observaciones del crítico pecan de ingenuas y muestran muchas fallas en el conocimiento de la psicología. Cualquiera que conozca un poco la obra de sor Juana puede darse cuenta de cómo escamotea su personalidad ante sus lectores y cómo produce una complicada obra —en ocasiones, naturalmente-, para que pocos la entiendan. Las innumerables páginas de sus comentaristas dedicadas a sus hipotéticos amores jamás han alcanzado comprobación alguna, misterio, indudablemente, que la escritora procuró conscientemente.

Sabemos también que las relaciones homosexuales, principalmente entre mujeres, eran violentamente condenadas en la época y en la Colonia. ¿Cómo esta escritora, inteligente y reservada hasta el extremo, cauta con sus circunstancias, cuidadosa de su fama, iba a ser tan ingenua como para desnudarse ante un público que sabía peligroso y adverso en ocasiones? Sólo un personaje muy ingenuo y muy torpe - que no lo era sor Juana- hubiera comentido un error de ese calibre, que la hubiera hundido como escritora, como mujer y como religiosa. 
A esto se refiere Paz en su obra, cuando afirma que los poemas de «amor» de la monja hay que verlos desde la tradición poética cortesana (págs. 262 y ss.) y subraya «la reserva y la economía» de la escritora (pág. 298) y su «tacto y habilidad política», que nunca le hubieran permitido mostrar sus sentimientos más íntimos. Paz se pregunta ¿por qué poemas a la virreina y no al virrey?, y responde: «Porque habría sido escandaloso dentro de la moral de la época (y aún en la nuestra) que sor Juana dedicase al marqués de la Laguna poemas en los que exaltase sus virtudes morales a la par que sus encantos físicos» (pág. 266). Es decir, la monja guarda un respeto absoluto a la moral reinante, lo cual le impediría en absoluto exhibir una amor plenamente satanizado dentro de esa moral.

Sin embargo Paz, cuando retoma la cuestión de la «virilidad» de sor Juana, aunque más cautamente, continúa algunas de las aserciones de Pfandl. Acepta que Juana transgrede su papel femenino (el papel de la mujer en la época), y «transgresión es virilización» (pág. 122), frase rotunda y difícil de aceptar. Sor Juana, afirma, «quiere apoderarse de los valores masculinos, porque quiere ser como un hombre» (pág. 159). Yo creo que estas líneas contienen algunos errores conceptuales. No me parece que quiera apoderarse de «los valores masculinos» en sí, porque muy claramente dice que no los estima demasiado, como puede verse en algunos poemas y en la carta a sor Filotea. De lo que quiere apoderarse es del saber, o de la posibilidad de adquirirlo. Lo cual significa que no quiere ser como un hombre, sino lograr algunas de las cosas alcanzables por el otro sexo, lo cual es muy diferente.

Rechaza Paz la «masculinidad» de sor Juana desde el punto de vista somático, pero no "desde el punto de vista psicológico, social e histórico» (pág. 159). Resulta triste que cualquier intento de una mujer por liberarse de los estrechos moldes que las diferentes épocas le han impuesto sea caracterizado de masculino. Como Pfandl exactamente, Paz cree que «el estado religioso fue la neutralización de su sexualidad corporal y la liberación y trasmutación de su libido» (pág. 159), lo cual es un imposible. La libido y la sexualidad pueden, en todo caso, reprimirse, y no hay muchas pruebas de que Juana Inés lo hiciera, por lo menos desde el punto de vista literario, que debería ser el que principalmente nos interesara. Hay, además, otra cuestión importante para matizar lo anterior. Por las muchas descripciones que existen sobre los conventos en el siglo XVII, podemos deducir que la sexualidad no estaba precisamente muy reprimida allí. En España, por ejemplo, la relajación en las órdenes religiosas de mujeres era desmesurada. Hoy existen datos sobre las "epidemias de endemoniados», de las que muchas monjas resultaban embarazadas; los raptos de novicias y los escalos de conventos eran habituales, hasta el punto de que fue necesario poner orden en 
tan desbocado problema, e incluso cerrar algunos monasterios ${ }^{10}$. En la Colonia probablemente la libertad era mucho mayor; «La laxitud de la moral sexual del pueblo mexicano seguramente es herencia de la Nueva España», dice Paz (pág. 107). Un ambiente erótico flotaba por todos los rincones del claustro, hasta en asuntos que parecían formar parte de la regla. El propio Pfandl se refiere, por ejemplo, a las flagelaciones, ampliamente conocidas como «el más pleniplacentero dolor o el más plenidoloroso placer» (pág. 52). Octavio Paz dedica un amplio capítulo («La celda y sus celadas»), a describir la vida de los conventos en la Nueva España, y advierte ahí la debilidad de las reglas y el incumplimiento de los votos, así como la profusa vida social, con fiestas, visitas hasta en las celdas, banquetes, música, etc. También Pfandl describe los conventos y el ambiente erótico que reinaba por doquier ${ }^{11}$. Todo lo cual no parece el entorno apropiado para reprimir la sexualidad, para hacer olvidar los atractivos del mundo exterior, ni para volver asexuada a una monja, llena de vida, inquieta y vivaz hasta en sus últimos días.

Los deficientes conocimientos psicoanalíticos de Pfandl, aunados a sus propias fantasías, le llevan a atribuir la supuesta masculinidad de sor Juana a su complejo de Edipo. Lo cual es un error de principio: el complejo de Edipo es un fenómeno universal (y en ese sentido, probablemente lo experimentaría la escritora), pero no es un camino hacia el cambio de sexo. El crítico alemán deduce, además, que Juana se colocó imaginariamente en el lugar de su madre, para "cumplir frente al padre el pretendido objeto-opción» (pág. 105); como no puede, adquiere complejo de masculinidad. Sigue con las lucubraciones fantásticas hasta la conclusión de que su confesor, Antonio Núñez de Miranda, sustituyó a la imagen paterna. Difícil sería una afirmación de tal categoría: parece desconocerse un sentimiento mucho más frecuente entre confesor y sujeto de confesión, que es la transferencia. Pero trabajar - de nuevo - con supuestos, se sale de cualquier estudio serio.

Paz también, tal vez influido por Pfandl, deja volar la fantasía en cuanto a la imagen paterna de Juana Inés. «Su ausencia era ocasión de nostalgia e idealización» (pág. 111), y la evocación del padre fue «una mezcla de resentimiento, nostalgia y — ¿por qué no? - secreta admiración» (pág. 112).

${ }^{10}$ Cfr. Gregorio Marañón, «Los misterios de San Plácido», en Don Juan, Madrid, Espasa Calpe, 1967.

${ }^{11}$ Por ejemplo, se refiere a las monjas flageladas por sus sirvientas, a las que pagaban ampliamente por este servicio; a los actos públicos, como aquél en que una hermana se presentaba todos los viernes en el refectorio, «donde se encontraban reunidas las monjas para la comida del mediodía, se quitaba el velo de la cabeza, se bajaba el hábito hasta la cintura y se azotaba y confesaba entre lágrimas, lamentos y exageraciones, los pequeños pecados e imperfecciones de la vida religiosa», Pfandl, pág. 52. 
Además, añade, lo mató imaginariamente, convirtiéndose en su viuda y él en el marido muerto (pág. 112). De ahí, también, deduce Paz la masculinización de la joven ${ }^{12}$. Durante varias páginas (112-117), juega con los posibles personajes masculinos con quienes pudo Juana identificarse y los fantasmas que tal vez poblaron su mente. Hacer deducciones de este tipo, que ni siquiera pueden apoyarse en la psicología, a nada conducen, sino tal vez a posibles desviaciones que, en caso de ser creíbles, pueden resultar peligrosas.

Para explicar los cambios que tienen lugar en la personalidad de sor Juana en cierta época de su vida, Pfandl recurre a la fisiología. Escribe un particular capítulo titulado "Algo sobre el climaterio y tipos de constitución» donde, basándose en estudios biológicos y anatómicos, realiza un estudio de tipo médico y clasificatorio sobre la menopausia; allí, según la ubicación de los diferentes países, determina la edad de la mujer en que tal proceso tiene lugar; divide a las mujeres en «intersexuales y pícnicas» y señala cómo ambos tipos se comportan en el matrimonio y muchos otros detalles de este tipo. A continuación coloca a sor Juana en el casillero preciso, según todo lo anterior, y llega a la conclusión de que su climaterio fue exactamente en 1693. A causa de esto, según nuestro crítico, «las agigantadas y excitadoras fuerzas del inconsciente» enmudecen (pág. 288), y cambia la actitud vital de la monja. Todas esas profusas y absurdas páginas deberían pasarse inmediatamente por alto porque, además de señalados errores, que son obvios, invaden unos terrenos que poco tienen que ver con un estudio psicológico, y menos literario.

Sin embargo, Paz interviene, lo discute y añade objeciones en el mismo terreno (pág. 605): Que la menopausia varía de mujer a mujer, que si afecta más a unas que a otras, etc. Es, en mi opinión, un tema que no debería haber entrado en su libro y cuyos comentarios sólo pueden explicarse por lo presente que está la obra de Pfandl en él.

He aquí, pues, dos libros más sobre sor Juana. Uno trata de ser un estudio psicoanalítico e -infortunadamente - no lo es en ningún momento. El otro no trata de serlo, pero recurre en algunas páginas a Freud y a cuestiones psicológicas, con poca fortuna. Algo que hubiese sido innecesario en una obra de alcances diferentes, y que sólo por contaminación de otra incurre en ese terreno tan poco preciso y tan mal apuntalado.

\footnotetext{
12 «En el caso de Juana Inés, si es verdadera mi suposición, la niña mata a su padre, no a su madre, y esto indica una inversión de sexo y de valores. Doble transgresión: matar a la imagen de su padre y asumir así, no la imagen de la madre, sino la masculina», Paz, pág. 112.
} 